\title{
ISOLATION OF CELLULAR FATTY ACID DISTRIBUTED IN UNKNOWN RHIZOBIAL STRAINS
}

\author{
O.N.Shanmugapriya and S.Priya*
}

P.G and Research Department of Microbiology, S.T.E.T. Women's College, Mannargudi, T.Nadu, India

P.G Department of Biotechnology, S.T.E.T. Women's College, Mannargudi, T.Nadu, India

Corresponding Author: piri_333@yahoo.co.in, +91 9787392903

\section{ABSTRACT}

Fatty acid (UFA) biosynthesis is essential for the maintenance of membrane structure and function in many groups of anaerobic bacteria. In this study isolation of cellular fatty acid distributed in unknown rhizobial strains collected from five different soil samples by pour plate method using YEMA medium. The five soil sample are namely Klt 1, Alg 2,Bdl 3, Rf 4 and Mdk 5.The isolated rhizobial sample was identified based on morphological and biochemical characterization. Then the purified culture was mass multiplied and used for isolation of fatty acid. The fatty acid profile of five different rhizobial isolates were identified by GC and the result of fatty acid was totally seven fatty acids from Rhizobial isolates. Among them the Myrestic acid (C:14) were present all the isolates respectively.

Key words: Myrestic acid; Rhizobial isolates;fatty acid; YEMA medilum.

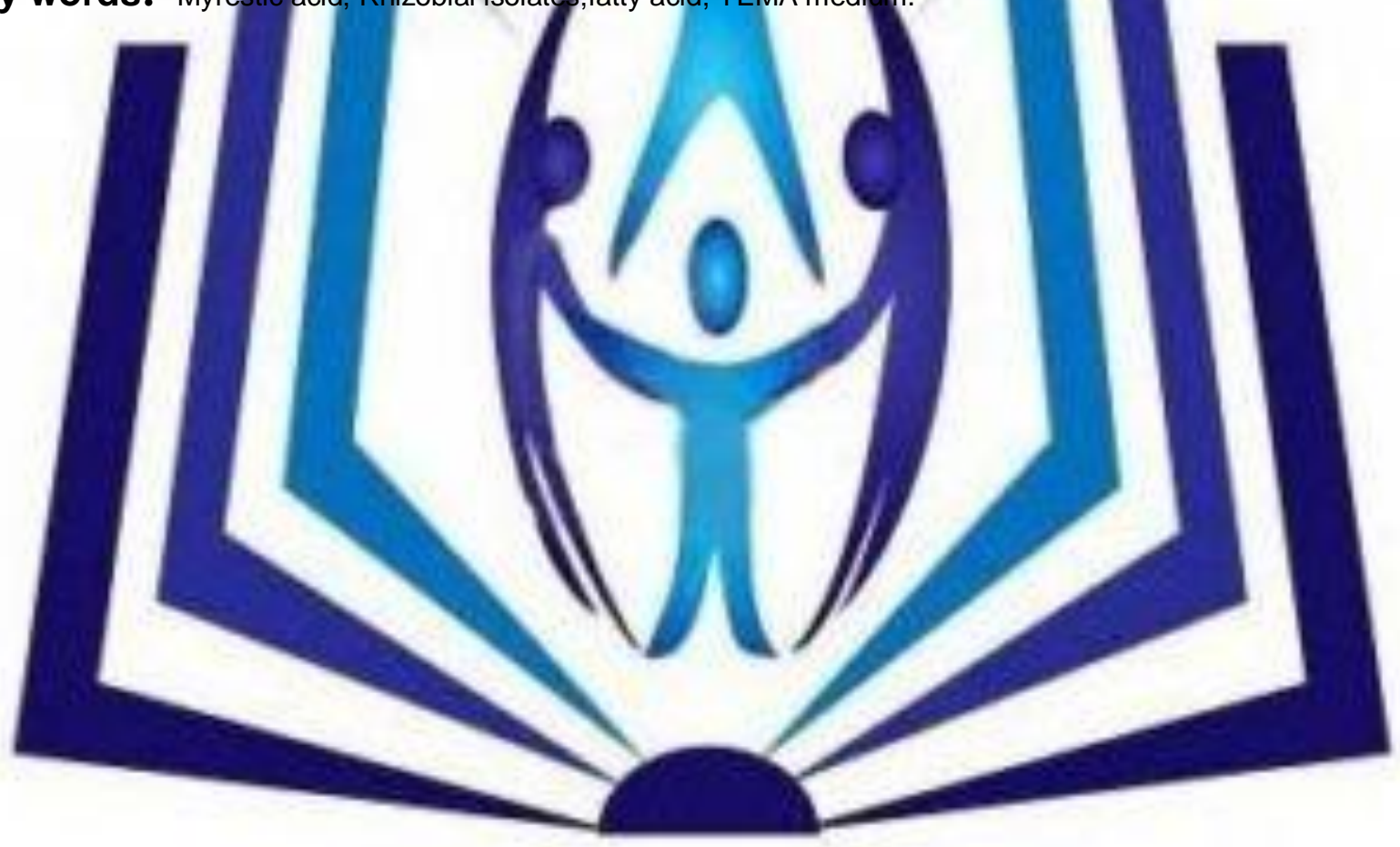

\section{Council for Innovative Research}

Peer Review Research Publishing System

Journal of Advances in Natural Sciences

Vol 2, No. 2

editorjansonline@gmail.com

www.cirworld.com 
worldwide (Postaga,1998). Considering the potential of legume-Rhizobium associations, rhizobial inoculants have been used to improve plant and soil health for more than a century now. Inherent with the use of bioinoculants is the problem of variability in field performance and successful establishment of introduced strains on account of competition with the indigenous rhizobacterial population (Grahm, 1988).

In rhizhobia reduce atmospheric nitrogen to ammonia using the enzyme nitrogenous and supply this essential nutrient to the host plant cells. Soil system supports a conglomerate of microorganisms with a high degree of diversity and their interactions are extremely complex. This sometimes creates a hostile environment for the inocula. The introduced microorganisms in the soil are also subjected to abiotic stress (Barnet et al., 1991). The ability of the inoculated strain of Rhizobium to outperform the indigenous population is termed as nodulation competitiveness.

In the present study, the attempt has been made to isolate and identify various rhizobial strains collected from five different soil samples from Thanjavur district. The biochemical characteristics were studied from the isolated strains. The isolated strains are mass multiplied to study the distribution of fatty acid present in the unknown rhizobial sample.

\section{MATERIAL AND METHODS}

\section{Collection of soil sample}

The soil sample are collected from five different localities Kalathur (Klt 1), Alangudi (Alg 2), Budalur (Bdl 3), Reserved forest (Rf 4) and Madhukur (Mdk 5) on Thanjavur District based on soil atlas.

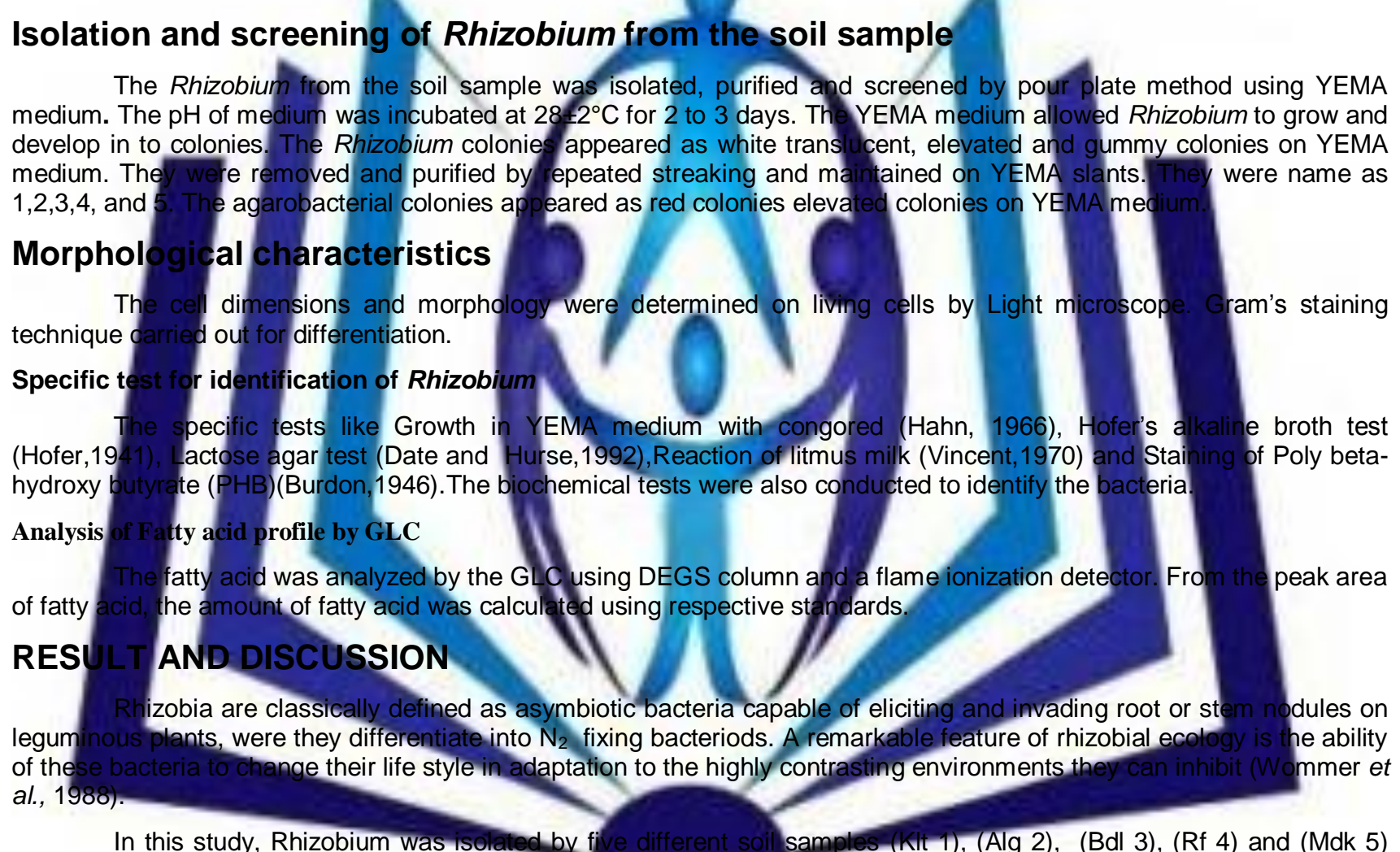
collected from various place of Thanjavur district by pour plate method using YEMA medium. All the isolates were purified and showed positive result in PHB test and failed to congo red in YEMA coloration was not found in lactose agar test, 3Ketolactose test and no growth was found in Hofer's alkaline agar and litmus milk reaction test of rhizobial isolates (Table1).Many workers surveyed many strains of rhizobia and used many cultural test, pointed out that the rhizobial typically show slow growth on peptone glucose agar, form little or no H2S from bismuth sulphite and no precipitate in glyceryl phosphate agar, not absorbing congo red and did not utilize citrate (Kleczkonwska et al., 1968; Jordon,1984).

The isolated culture were identified by various morphological and biochemical methods as showed in table-2. The result clearly indicate all the Rhizobium were gram-negative, rod shaped and motile in nature ,the cell diameter of all rhizobial isolates ranged from 0.5 to $3 \mu \mathrm{m}$ respectively. The result of biochemical tests showed all the positive result in all the rhizobial isolates and negative result in methyl red test, VP test, triple sugar iron and oxidase test. The isolated culture was mass multiplied using YEMA broth and culture was used by seed treatment.

Tighe et al., (2000) reported that the fatty acid profile of Meso Rhizobium, Bady Rhizobium and Sino rhizobium were evaluated using GC. The clustering of rhizobial species based on fatty acid analysis is usual because several separate clusters are observed form it (Jarvis et al., 1989)

Fatty acid of five Rhizobial sample was investigated by GC and the result of fatty acid was totally seven fatty acids from Rhizbial isolates. One fatty acid was belonged to saturated and the remaining six were found to be 
unsaturated. Among

them

the

Myrestic

acid

(C:14

) were present all the isolates. The maximum number of fatty acids (6) was detected from ALg2, Bld3 and MDk5 followed by Rf4 different fatty acids respectively.

\section{REFERENCES}

1. Postaga J., 1998. Nitrogen fixation. Cambridge university press, Cambridge.311-329.

2. Grahm P.H., 1988. Antibiotic sensitivities of the rot nodule bacteria.Aust. J.Biol.Sci., 16:557-559.

3. Barnet Y., Dadarwal. H., and Mathew A., 1991. Ecology of legume root nodules bacteria.In: studies in plant Scineces .Biol. And Biochem., 199-208.

4. Hahn., 1966. Control of fatty acid desaturation: a mechanism conserved from bacteria to humans. Mol. Microbiol., 62:1507- 1514.

5. Hofer., 1941. Rapid method of total lipid extraction and purification. Can. J. Biochem. Physiol., 31:911-917.

6. Date and Hurse., 1992. Evaluation of some flax genotypes straw yield, yield components and technological characters. J. of Natural Fibers, 1(2): 1-12.

7. Vincent., 1970. Biochemical testing of microorganism. In: Medical for tropical countries. Microbiol. Low price edition. Butterwoth-Heineman Ltd., Oxford, 11: P.479.

8. Burdon, 1946. Tissue culture and the selection of resistance to pathogens. Annu Rev Phytopathol 24: $159-186$.

9. Wommer Chol, and C. O. Rock. 1988. A new mechanism for anaerobic unsaturated fatty acid formation in Streptococcus pneumoniae. J. Biol. Chen. 277:44809-44816.

10. Kleczkonwska, Birge, and P. R. Vagelos., 1968. Evidence for two genes specifically involved-in-unsaturated fatty acid biosynthesis in Escherichia coli. J. Bacteriol. 100:601-604.

11. Jordon, 1984. A bacterium that has three pathways to regulate membrane lipid fluidity. Mol. Microbiol. 60:25625 12. Tighe, Nayar S.L., and Chopra 2000. Daillel cross analy
J.Plant Production, Mansoura Univ., Vol. 1 (9): 1219-1231

13. Jarvis, Hammer J.E., and Holden ., 1989. Linking approaches

Daillel cross analysis for straw, seed yields and their components in flax.

Table-1:

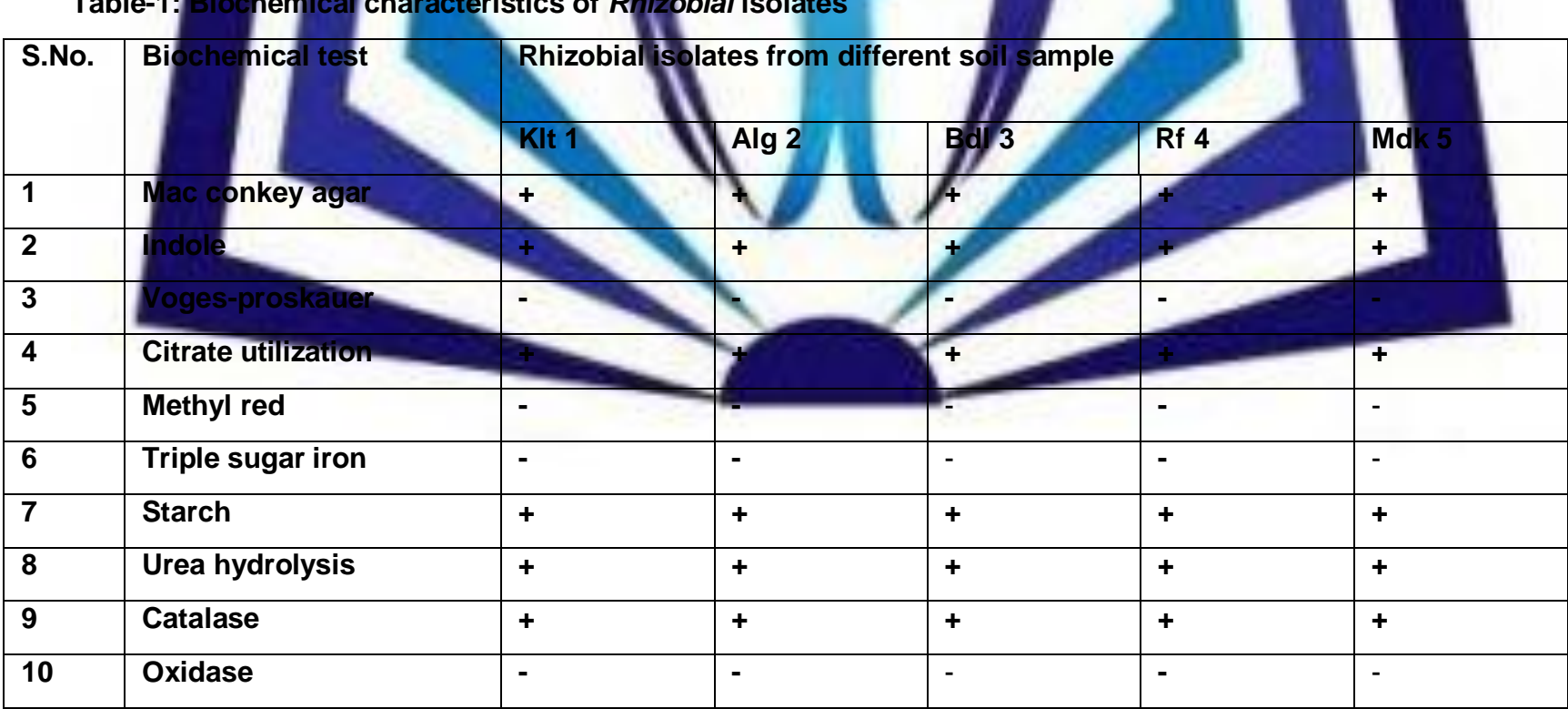

+ denote positive

- denote negative

Kalathur (KIt 1)

Alangudi (Alg 2) 


\section{Budalur (Bdl 3)}

Reserved forest (Rf 4)

Madhukur (Mdk 5)

Table-2: Estimation of fatty acid profile in different Rhizobial isolates(mg/g/of lipid)

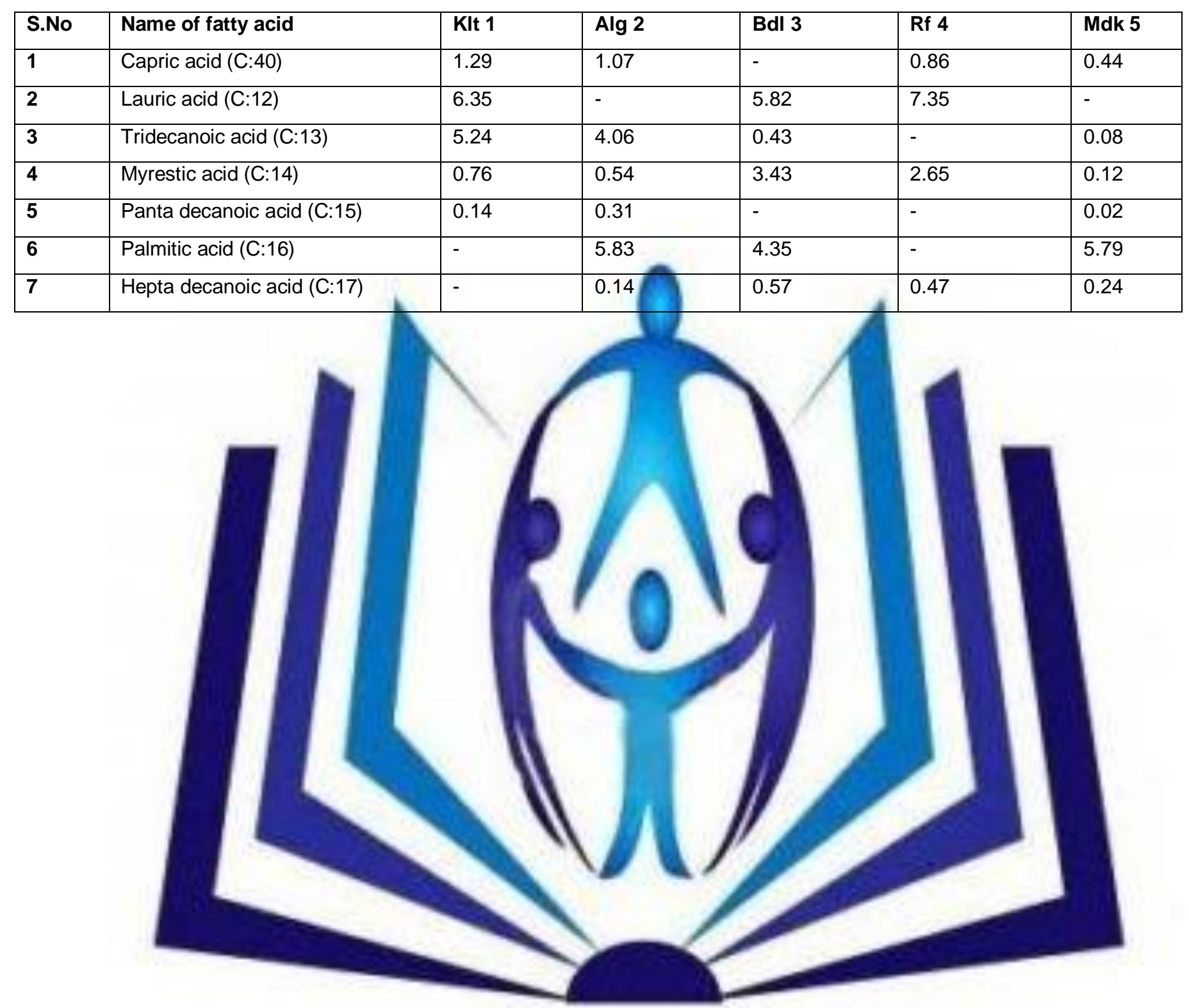

